\title{
Continuous Fixed-Bed Column Study and Adsorption Modeling: Removal of Lead Ion from Aqueous Solution by Charcoal Originated from Chemical Carbonization of Rubber Wood Sawdust
}

\author{
Swarup Biswas ${ }^{1}$ and Umesh Mishra ${ }^{2}$ \\ ${ }^{1}$ Department of Environmental Engineering, NIT Agartala, Tripura 799046, India \\ ${ }^{2}$ Department of Civil Engineering, NIT Agartala, Tripura 799046, India \\ Correspondence should be addressed to Swarup Biswas; swarup.biswas85@gmail.com
}

Received 15 August 2015; Accepted 18 October 2015

Academic Editor: Wenshan Guo

Copyright (C) 2015 S. Biswas and U. Mishra. This is an open access article distributed under the Creative Commons Attribution License, which permits unrestricted use, distribution, and reproduction in any medium, provided the original work is properly cited.

\begin{abstract}
The efficiency of chemically carbonized rubber wood sawdust for the removal of lead ion from the aqueous stream was investigated by column process. Chemically carbonized rubber wood sawdust was prepared by treating the sawdust with $\mathrm{H}_{2} \mathrm{SO}_{4}$ and $\mathrm{HNO}_{3}$. Maximum removal of lead ion in column process was found as $38.56 \mathrm{mg} / \mathrm{g}$. The effects of operating parameters such as flow rate, bed depth, concentration, and $\mathrm{pH}$ were studied in column mode. Experimental data confirmed that the adsorption capacity increased with the increasing inlet concentration and bed depth and decreased with increasing flow rate. Thomas, Yoon-Nelson, and Adams-Bohart models were used to analyze the column experimental data and the relationship between operating parameters. Chemically carbonized rubber wood sawdust was characterized by using Fourier transform infrared spectroscopy. Scanning electron microscope was also utilized for morphological analysis of the adsorbent. Furthermore X-ray fluorescence spectrum analysis and energy dispersive X-ray spectroscopy were also used for the confirmation of lead adsorption process.
\end{abstract}

\section{Introduction}

Pollution due to lead contamination in the water stream has become a serious problem nowadays. Lead poisoning causes several types of damage to human health such as kidney, nervous system, liver, and brain damage that can lead to death $[1,2]$. Major sources from where the lead is discharging are mining wastes, chemical industries, lead acid storage batteries, and ceramic and glass industries. Environmental Protection Agency (EPA) has given some standard for drinking water which is $0.05 \mathrm{mg} / \mathrm{L}$ [3].

Therefore, in order to reduce the harmful effect of lead contamination in the environment, it is necessary to treat the lead contaminated wastewater before discharge. Many types of treatment system like ion exchange, coagulation, chemical precipitation, membrane filtration, electrodeposition, solvent extraction, and adsorption have been proposed for lead removal from the lead contaminated wastewater. Among all the methods for removal of lead ion adsorption is apparently the most efficient method, due to its simplicity, higher removal capacity, and low operating cost. Numerous adsorbents like green coconut shells [4], wheat bran [5], cortex fruit wastes [6], agave bagasse [7], and modified Agaricus bisporus [8] have been used to remove the lead ion from aqueous solutions. Most of the adsorption experiment is limited to batch experiments which do not give accurate scale-up data that can be used for large scale of treatment.

The objective of this study was to evaluate the performance of the chemically carbonized rubber wood sawdust (CRSD) column for the removal of lead ion from the lead contaminated waste stream. Dynamic behavior of fixed-bed column was described in terms of breakthrough curve. As part of this study, effects of bed depth, flow rate, and initial feed concentration on the performance of lead adsorption 
onto CRSD were investigated. Different models such as Thomas, Yoon-Nelson, and Adams-Bohart models were used to compare the experimental data.

\section{Materials and Methods}

2.1. Preparation of Biomass. Adsorbent was prepared by chemical carbonization of the rubber wood sawdust which was collected from rubber wood processing industry, Nagechera, Tripura, India. $10 \mathrm{~g}$ of rubber wood sawdust was added to $11 \mathrm{~mL}(98 \% \mathrm{~m} / \mathrm{m})$ of sulphuric acid and after 10 minutes $6.6 \mathrm{~mL}$ of concentrated nitric acid $(65 \% \mathrm{~m} / \mathrm{m})$ was added to the mixture. Black slurry was transferred to the oven at $150^{\circ} \mathrm{C}$. After 24 hours of heating the black slurry was centrifuged with distilled water to separate the carbonized charcoal and to make the $\mathrm{pH}$ neutral. Then carbonized sawdust was dried at $110 \pm 2^{\circ} \mathrm{C}$ and screened for the desired particle size $(0.5-1 \mathrm{~mm})$.

2.2. Analysis and Characterization. For the determination of moisture content of CRSD Karl Fisher instrument (1204R of VMHI, Metrohm Ltd., USA) was used. Specific surface area and pore volume of CRSD were measured by Brunauer-Emmett-Teller (BET) method and for that purpose Micromeritics automatic surface area analyzer (Gemini 2360, Shimadzu, Japan) was utilized. The X-ray fluorescence (XRF) spectrum analysis (Model Phillips PW2404, PANalytical) was used to determine the percentage of elements present in CRSD before and after adsorption of lead ion. The concentrations of the lead ion in synthetic solutions were determined by using atomic absorption spectrophotometer (Perkin Elmer Model AAS 700). For determination of $\mathrm{pH}$ the portable $\mathrm{pH}$ meter (Hach) was utilized. Absorbance spectra were determined by using UV-Vis spectrophotometer (Hach, DR5000). Functional groups of the adsorbent were identified by the Fourier transform infrared spectroscopy (FTIR) (Bruker 3000 Hyperion, Germany). Morphological analysis of the adsorbent was done by using the scanning electron microscope (SEM) (JELO JSM7600F) supported by EDS (energy dispersive X-ray spectroscopy) (Oxford AZtec energy system).

2.3. Reagents. The chemicals used in the experiment were of analytical reagent grade. Sulphuric acid $\left(\mathrm{H}_{2} \mathrm{SO}_{4}\right)$ and nitric acid $\left(\mathrm{HNO}_{3}\right)$ from Merck, India, were utilized for the treatment of sawdust. A stock solution of $1000 \mathrm{mg} / \mathrm{L}$ was prepared through dissolution of appropriate amount of $\mathrm{Pb}\left(\mathrm{NO}_{3}\right)_{2}$ (Merck, India) salt in deionized water. The stock solution was diluted to obtain the required concentration used in the experiment. For $\mathrm{pH}$ adjustment $0.1 \mathrm{M}$ caustic soda $(\mathrm{NaOH})$ and hydrochloric acid solution $(\mathrm{HCl})$ were used.

2.4. Column Data Analysis. Dynamic column studies were carried out in a glass column of $2.54 \mathrm{~cm}$ internal diameter and $10 \mathrm{~cm}$ height. A peristaltic pump was used to maintain the desired flow rate. In the bottom side $0.05 \mathrm{~cm}$ thick glass wool was placed to prevent any loss of adsorbent and was to give mechanical support to the adsorbent bed. Total
TABLE 1: Characteristics of the adsorbent.

\begin{tabular}{lc}
\hline Parameters & Value \\
\hline Moisture content $(\%)$ & 13.2 \\
Solubility in water $(\%)$ & 0 \\
Solubility in $0.25 \mathrm{M} \mathrm{HCl}(\%)$ & 0 \\
BET surface area $\left(\mathrm{m}^{2} / \mathrm{g}\right)$ & 1400 \\
Average pore diameter $(\AA)$ & 42.6 \\
Total pore volume $\left(\mathrm{cm}^{3} / \mathrm{g}\right)$ & 1.82 \\
\hline
\end{tabular}

experiment was carried out at room temperature $30 \pm 2^{\circ} \mathrm{C}$. Effects of process parameter like flow rates $(10,15$, and $20 \mathrm{~mL} / \mathrm{min})$, bed depth $(2,5$, and $7 \mathrm{~cm})$, concentration (10, 20 , and $30 \mathrm{mg} / \mathrm{L})$, and $\mathrm{pH}(3.1,5.2$, and 6.4) were investigated. Samples were collected every half an hour from the bottom of the column and were tested to know the lead concentration. The column performance was investigated by calculating the breakthrough time and adsorption capacity. Adsorption capacity at $10 \%$ breakthrough was calculated according to [9]

$$
q_{B}=\left(\frac{x}{m}\right)_{B}=\frac{x_{B}}{m_{\text {adsorbent }}}=Q_{v}\left(C_{0}-\frac{C_{B}}{2}\right) \frac{t_{B}}{m_{\text {adsorbent }}},
$$

where $C_{0}$ is influent concentration, $x_{B}$ is mass of metal ion adsorbed in the column at breakthrough $(\mathrm{mg}), m_{\text {adsorbent }}$ is mass of adsorbent in the column $(\mathrm{g}), Q_{v}$ is flow rate $(\mathrm{mL} / \mathrm{min}), C_{0}$ is influent metal ion concentration $(\mathrm{mg} / \mathrm{L}), C_{B}$ is breakthrough metal ion concentration $(\mathrm{mg} / \mathrm{L})$, and $t_{B}$ is time to breakthrough ( $\mathrm{min})$.

\section{Results and Discussion}

3.1. Characterizations of the Adsorbent. Characteristics of CRSD were illustrated in Table 1 where higher specific surface area and pore volume were observed which indicated the CRSD as an efficient adsorbent. The feasibility of the lead adsorption onto CRSD was checked by XRF analysis shown in Table 2. It was observed that after adsorption of lead ion percentage of other elements such as $\mathrm{Na}, \mathrm{K}$, and $\mathrm{Ca}$ was decreased and $3.125 \%$ lead appeared. In this case other elements may be involved in ion exchange process with the lead ion and their percentages were decreased. Identification of the functional groups present in the adsorbent was carried out by using FTIR analysis (Figures 1 and 2). The major peaks found in the CRSD were at $1708.58 \mathrm{~cm}^{-1}, 1612.56 \mathrm{~cm}^{-1}$, and $1162.34 \mathrm{~cm}^{-1}$ which represented the presence of $\mathrm{C}=\mathrm{O}$ group, $-\mathrm{COO}^{-}$group, and $\mathrm{C}-\mathrm{O}$ group. Another peak at $3419 \mathrm{~cm}^{-1}$ represents the presence of $\mathrm{O}-\mathrm{H}$ starch which is due to carboxyl group $(\mathrm{O}=\mathrm{C}-\mathrm{OH}$ and $\mathrm{C}-\mathrm{OH})$. After adsorption the shifting of the peaks was observed which also justifies the feasibility of the adsorption process.

SEM micrograph (Figure 3) with higher magnification confirmed the large porous structure of CRSD. Adsorbent having large pore size has the higher adsorption capacity. Furthermore highly porous adsorbents which have organic functional groups have the higher metal capturing capacity. After adsorption of lead ion morphological structure of the CRSD was changed and this was shown in Figure 4. EDS 
TABLE 2: XRF analysis on the CRSD before and after adsorption of lead (\%).

\begin{tabular}{lcc}
\hline Elements & CRSD & Lead-loaded CRSD \\
\hline $\mathrm{O}$ & 31.24 & 24.183 \\
$\mathrm{C}$ & 61.41 & 60.17 \\
$\mathrm{Na}$ & 0.020 & 0.001 \\
$\mathrm{Ca}$ & 0.427 & 0.19 \\
$\mathrm{~Pb}$ & - & 3.125 \\
$\mathrm{~S}$ & 0.643 & 0.069 \\
$\mathrm{Cl}$ & 0.190 & 0.097 \\
$\mathrm{~K}$ & 2.123 & 0.216 \\
\hline
\end{tabular}

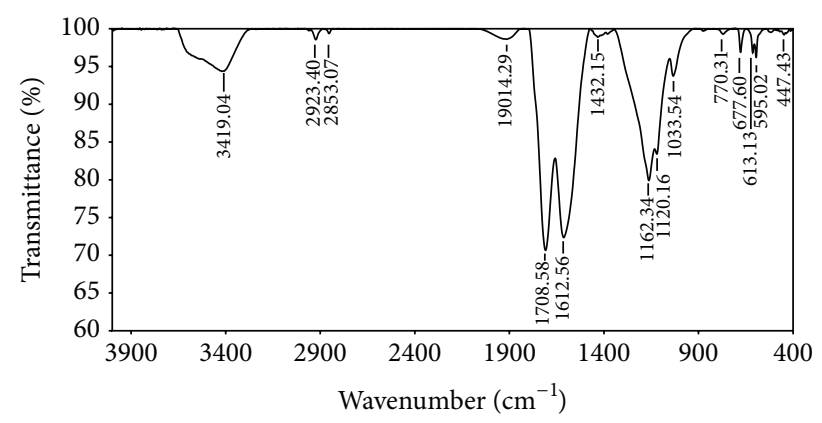

FIGURE 1: FTIR spectra of CRSD.

results (shown in Figures 5 and 6) confirmed the presence of lead ion after adsorption process.

3.2. Selectivity of the Lead Ion. As various cations and anions are present in wastewater ion selectivity is the important factor for real case of application. Selectivity of CRSD for lead ion was investigated in presence of anions $\left(\mathrm{NO}^{2-}, \mathrm{NO}^{3-}\right.$, $\mathrm{CO}_{3}{ }^{2-}, \mathrm{SO}_{4}{ }^{2-}, \mathrm{SO}_{3}{ }^{2-}$, and $\left.\mathrm{PO}_{4}{ }^{3-}\right)$ and cations $\left(\mathrm{Ca}^{2+}, \mathrm{Mg}^{2+}\right.$, $\mathrm{Cr}^{6+}, \mathrm{Al}^{3+}, \mathrm{Cu}^{2+}, \mathrm{Ni}^{2+}, \mathrm{Mn}^{2+}, \mathrm{Zn}^{2+}, \mathrm{Co}^{2+}, \mathrm{Cd}^{2+}, \mathrm{Pb}^{2+}, \mathrm{Hg}^{2+}$, and $\mathrm{Fe}^{3+}$ ). For this study $10 \mathrm{mg}$ of CRSD was used at $\mathrm{pH}$ of 5.2 and the volume was $20 \mathrm{~mL}$. The color profile and UV spectra of CRSD for lead ion over a series of other coions were studied where lead concentration was $1.0 \mathrm{mg} / \mathrm{L}$ and each cation concentration was $20 \mathrm{mg} / \mathrm{L}$. Ion selectivity study for anions was conducted by using the concentration of $150 \mathrm{mg} / \mathrm{L}$ and lead concentration of $1.0 \mathrm{mg} / \mathrm{L}$. In these studies no considerable spectral inferences were observed at $550 \mathrm{~nm}$ which may be due to high bonding affinity between the CRSD and lead ion.

3.3. Column Data Analysis. Breakthrough behavior of the column adsorption process at different flow rates was investigated. Constant inlet breakthrough time and exhaustion time for lead adsorption onto CRSD increase with the decreasing in flow rate from 15 to $20 \mathrm{~mL} / \mathrm{min}$ (Figure 7), a trend similar to the other research work found in literature [10]. An increase in flow rate decreases the contact time of the adsorbent and adsorbate causing reduction in adsorption capacity and service time of the bed.

Breakthrough curves obtained at different bed depth $(2,5$, and $7 \mathrm{~cm}$ ) with a constant influent concentration of $20 \mathrm{mg} / \mathrm{L}$

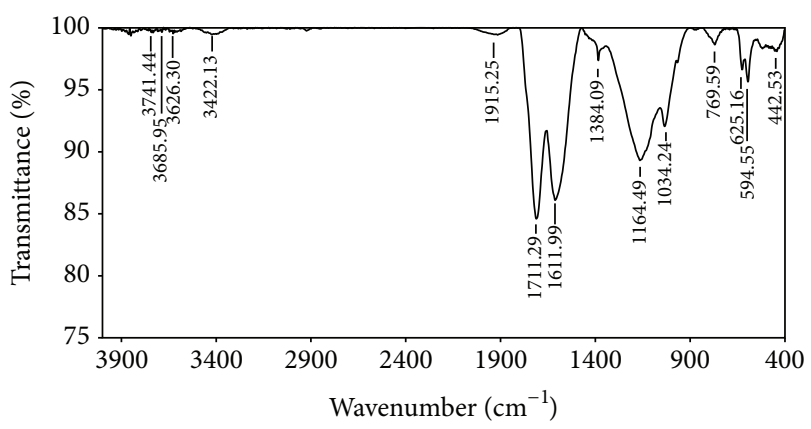

FIgURE 2: FTIR spectra of lead ion loaded CRSD.

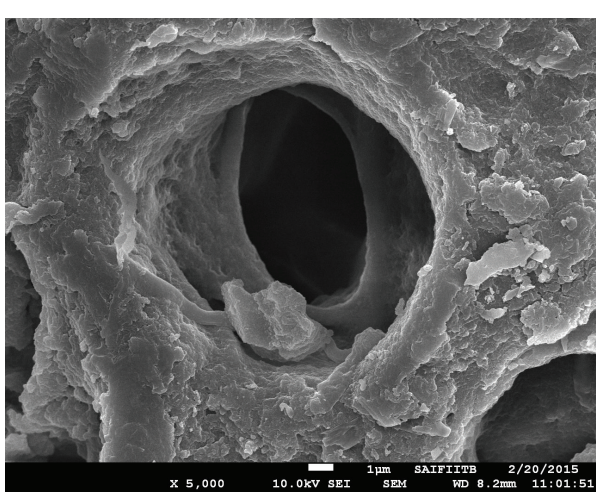

FIGURE 3: SEM image of CRSD.

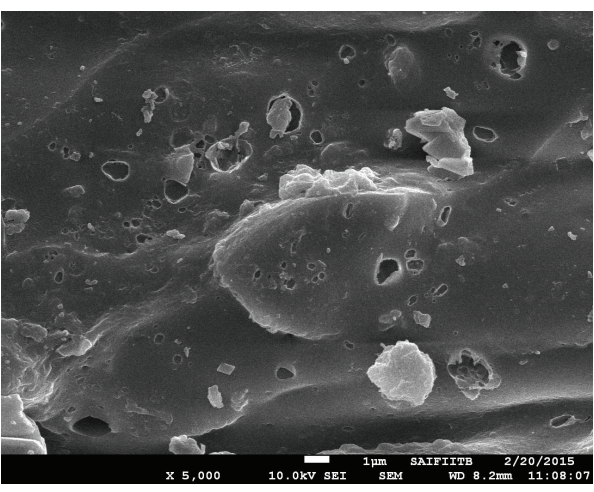

Figure 4: SEM image of lead ion loaded CRSD.

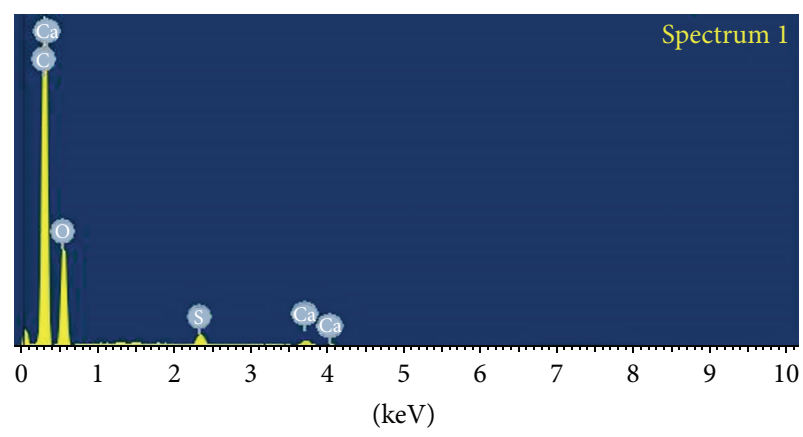

Full scale 14190 cts cursor: 0.000

Figure 5: EDS spectra of CRSD. 
TABLe 3: Parameters in fixed-bed column for lead adsorption by CRSD.

\begin{tabular}{|c|c|c|c|c|c|c|c|c|}
\hline$C_{0}(\mathrm{mg} / \mathrm{L})$ & $Q_{V}(\mathrm{~mL} / \mathrm{min})$ & $Z(\mathrm{~cm})$ & $\mathrm{pH}$ & $m_{\text {adsorbent }}(\mathrm{g})$ & $V_{B}(\mathrm{~mL})$ & $t_{B}(\min )$ & $C_{B}(\mathrm{mg} / \mathrm{L})$ & $q_{B}(\mathrm{mg} / \mathrm{g})$ \\
\hline 20 & 15 & 2 & 5.2 & 1.12 & 1350 & 90 & 2 & 21.70 \\
\hline 20 & 15 & 5 & 5.2 & 2.52 & 4950 & 330 & 2 & 35.36 \\
\hline 20 & 15 & 7 & 5.2 & 3.501 & 7200 & 480 & 2 & 37.02 \\
\hline 20 & 10 & 5 & 5.2 & 2.51 & 4800 & 480 & 2 & 34.42 \\
\hline 20 & 15 & 5 & 5.2 & 2.52 & 4950 & 330 & 2 & 35.36 \\
\hline 20 & 20 & 5 & 5.2 & 2.501 & 3600 & 180 & 2 & 25.91 \\
\hline 10 & 15 & 5 & 5.2 & 2.54 & 6750 & 450 & 1 & 23.92 \\
\hline 20 & 15 & 5 & 5.2 & 2.52 & 4950 & 330 & 2 & 35.36 \\
\hline 30 & 15 & 5 & 5.2 & 2.521 & 3600 & 240 & 3 & 38.56 \\
\hline 20 & 15 & 5 & 3.1 & 2.502 & 1800 & 120 & 2 & 12.95 \\
\hline 20 & 15 & 5 & 5.2 & 2.52 & 4950 & 330 & 2 & 35.36 \\
\hline 20 & 15 & 5 & 6.4 & 2.61 & 4500 & 300 & 2 & 31.034 \\
\hline
\end{tabular}

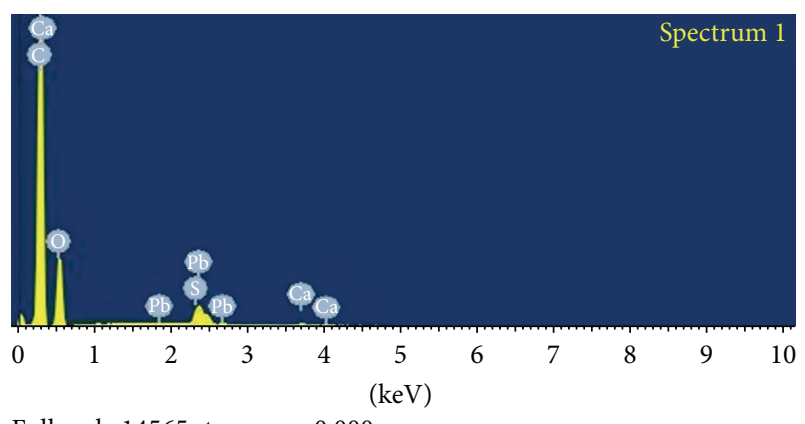

Full scale 14565 cts cursor: 0.000

FIGURE 6: EDS spectra of lead ion loaded CRSD.

and flow rate of $15 \mathrm{~mL} / \mathrm{min}$ are shown in Figure 8. From the figure it is observed that time of breakthrough and time of exhaustion increase with the increasing bed depth. According to Table 3 as the bed depth is increased adsorption capacity at $10 \%$ breakthrough is also increased and the similar tendency is also reported in literature [10]. At lowest bed depth there is no sufficient time for lead ions to diffuse into the holes of CRSD.

Initial metal ion concentration has a significant effect on breakthrough curve shown in Figure 9. Curves demonstrate that as the initial metal ion concentration increases breakthrough time and exhaustion time decrease. Experimental results are shown in Table 3 where adsorption capacity increases with the increasing concentration of 10 to $30 \mathrm{mg} / \mathrm{L}$ and the results comply with the results of other researchers [17].

$\mathrm{pH}$ of metal solution is another important parameter that has a great impact on adsorption process. Breakthrough curves at three different $\mathrm{pH}$ values (3.1, 5.2, and 6.4) are shown in Figure 10. It is shown in Table 3 that in lower $\mathrm{pH}$ adsorption capacity is less. Ionic groups of the adsorbent are positively charged in lower $\mathrm{pH}$ which restricts the adsorption of positive cations like lead. On the other hand in higher $\mathrm{pH}$ there is a formation of hydroxide which also restricts the adsorption process.

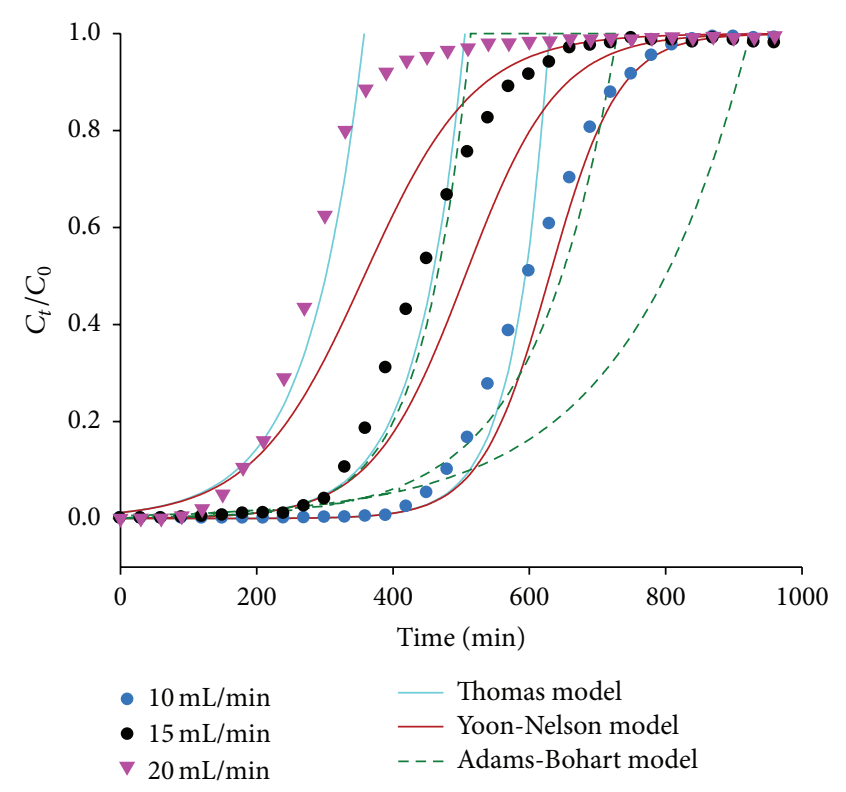

FIGURE 7: Effect of flow rate on breakthrough curve (concentration $20 \mathrm{mg} / \mathrm{L}$; bed depth $5 \mathrm{~cm}$; pH 5.2).

Bohart and Adams model is applied to check the dynamic behavior of the column. The equation is expressed as [18]

$$
\ln \left(\frac{C_{t}}{C_{0}}\right)=k_{\mathrm{AB}} C_{0} t-k_{\mathrm{AB}} N_{0}\left(\frac{Z}{U_{0}}\right) .
$$

Influent and effluent concentrations $(\mathrm{mg} / \mathrm{L})$ are denoted as $C_{0}$ and $C_{t} . k_{\mathrm{AB}}$ represents the kinetic constant $(\mathrm{L} / \mathrm{mg}$ $\min ), N_{0}$ is the saturation concentration $(\mathrm{mg} / \mathrm{L}), t$ is the flow time (min), $Z$ stands for bed depth of the fixed-bed column $(\mathrm{cm})$, and $U_{0}$ is the superficial velocity $(\mathrm{cm} / \mathrm{min})$. A plot of $\ln \left(C_{t} / C_{0}\right)$ versus $t$ gives the value of correlation coefficients $\left(R^{2}\right), k_{\mathrm{AB}}$, and $N_{0}$. Values of $R^{2}, k_{\mathrm{AB}}$, and $N_{0}$ are given in Table 4 . Values of $k_{\mathrm{AB}}$ decrease with increasing concentration and flow rate whereas they increase with increasing bed depth. The values of $R^{2}$ fluctuate from 0.32 to 0.90 which is not a good fitting with the experimental breakthrough curve. 


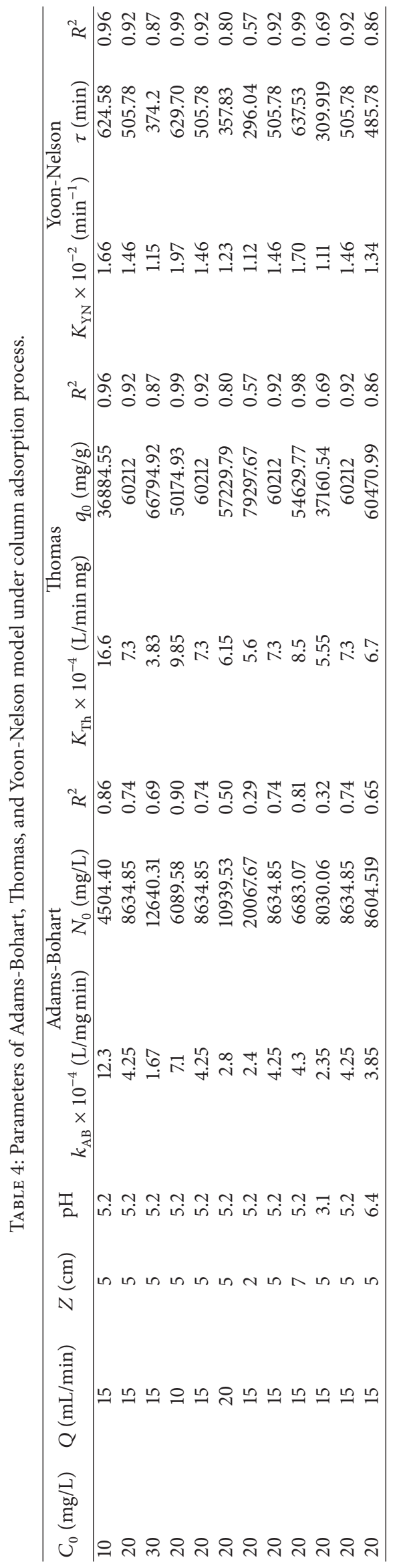




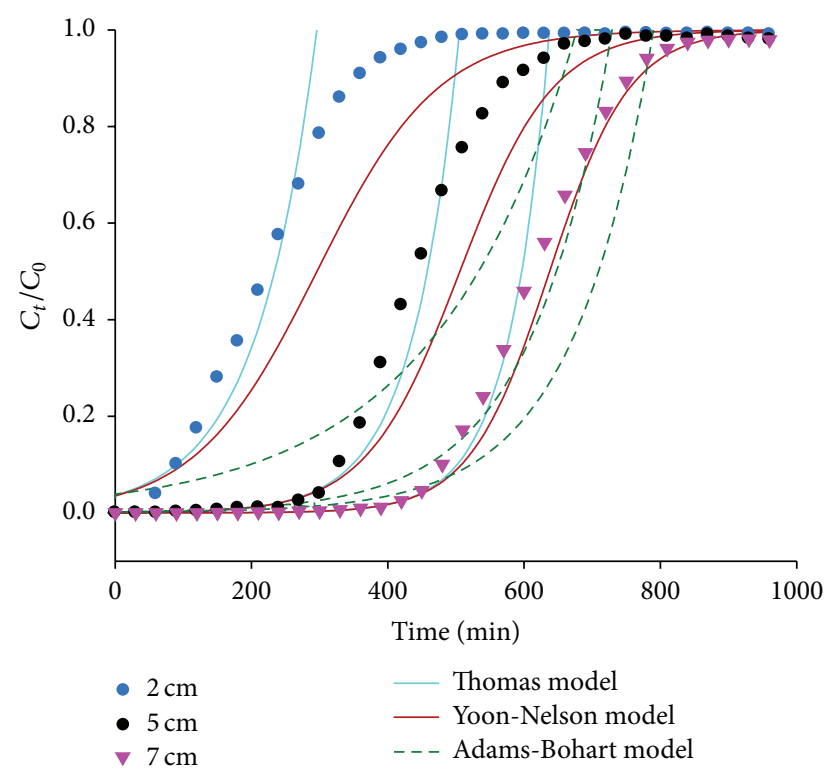

FIGURE 8: Effect of bed depth on breakthrough curve (flow rates $15 \mathrm{~mL} / \mathrm{min}$; concentration $20 \mathrm{mg} / \mathrm{L} ; \mathrm{pH}$ 5.2).

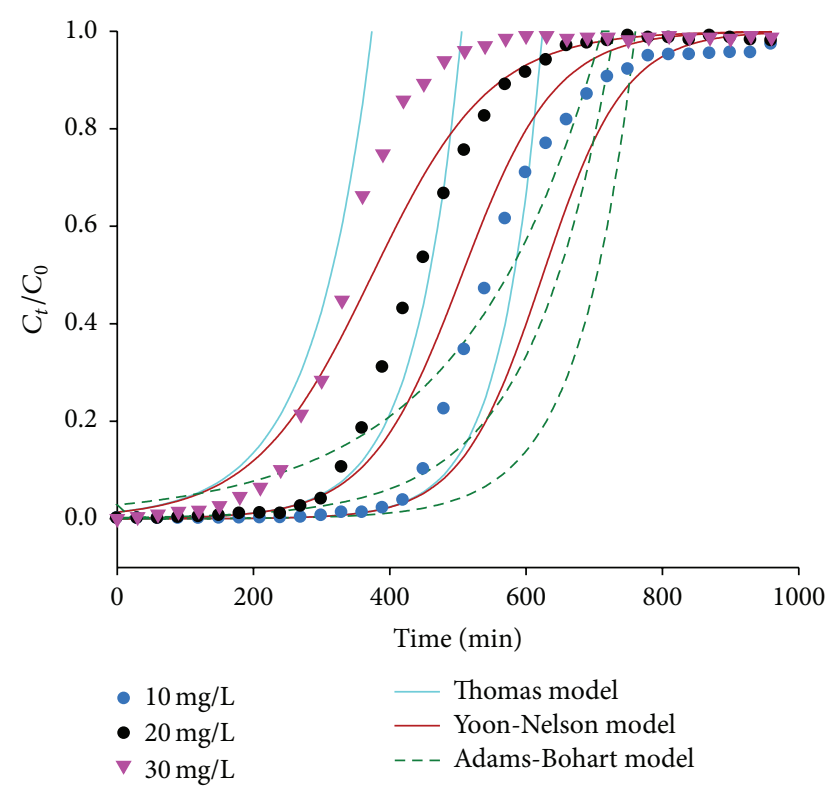

FIGURE 9: Effect of initial concentration on breakthrough curve (flow rates $15 \mathrm{~mL} / \mathrm{min}$; bed depth $5 \mathrm{~cm}$; $\mathrm{pH} 5.2$ ).

For the evaluation of breakthrough results Thomas model is applied to the experimental data of the column studies. The linearized form of the Thomas model is expressed as [19]

$$
\ln \left(\frac{C_{0}}{C_{t}}-1\right)=\frac{k_{\mathrm{Th}} q_{0} m}{Q}-k_{\mathrm{Th}} C_{0} t
$$

where $k_{\mathrm{Th}}$ is the Thomas kinetic coefficient ( $\left.\mathrm{mL} / \mathrm{min} \mathrm{mg}\right), t$ is the total flow time ( $\mathrm{min}$ ), and $Q$ is the volumetric flow rate $(\mathrm{mL} / \mathrm{min})$. Adsorption capacity and mass of the adsorbent are denoted as $q_{0}(\mathrm{mg} / \mathrm{g})$ and $m(\mathrm{~g})$. Plot of $\ln \left[\left(C_{0} / C_{t}\right)-1\right]$ versus $t$ gives the value of $k_{\mathrm{Th}}$ and $q_{0}$ which are illustrated in Table 4 .

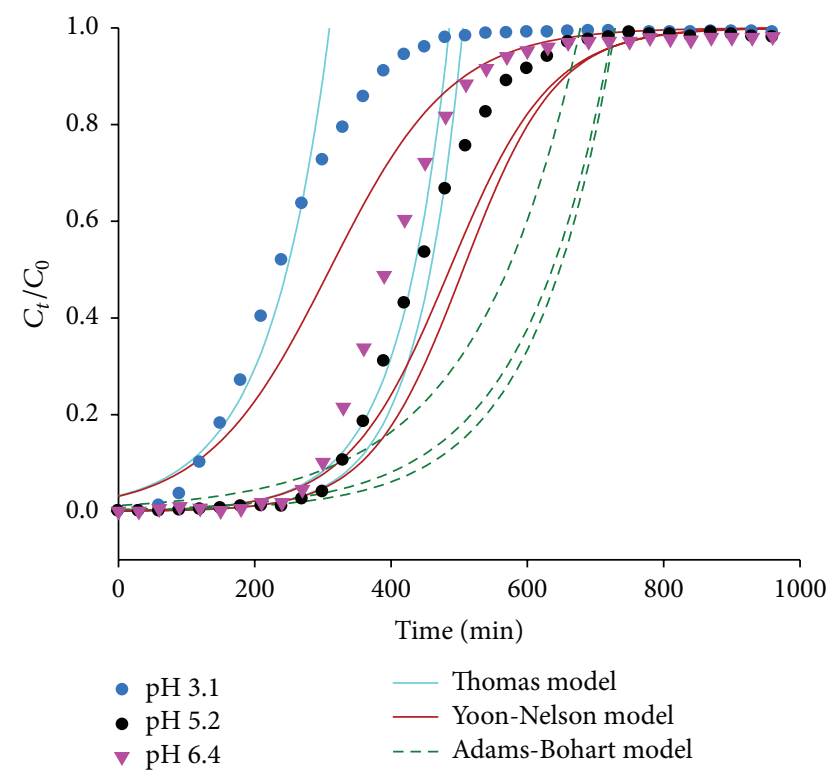

FIGURE 10: Effect of $\mathrm{pH}$ on breakthrough curve (bed depth $5 \mathrm{~cm}$; concentration $20 \mathrm{mg} / \mathrm{L}$; flow rates $15 \mathrm{~mL} / \mathrm{min}$ ).

The values show that $q_{0}$ values increased with the increasing in influent concentration and $\mathrm{pH}$, whereas the $q_{0}$ values decrease with the increase in bed depth. On the other hand $k_{\mathrm{Th}}$ decreases with increasing flow rate and concentration while it increases with the increase in bed depth. $R^{2}$ value is ranged from 0.57 to 0.99 which indicates the good fitting of the model with the experimental breakthrough curve.

Yoon and Nelson [20] model is also applied to check the experimental data which is expressed as

$$
\ln \left(\frac{C_{t}}{C_{0}-C_{t}}\right)=k_{\mathrm{YN}} t-\tau k_{\mathrm{YN}},
$$

where $\tau$ is the time required for $50 \%$ adsorbate breakthrough (min), $t$ is sampling time (min), and $k_{\mathrm{YN}}$ is the rate constant $\left(\min ^{-1}\right)$. The value of $k_{\mathrm{YN}}$ and $\tau$ can be found by plotting the graph between $\ln \left(C_{t} /\left(C_{0}-C_{t}\right)\right)$ and $t$ which is shown in Table 4 . The values of $R^{2}$ found in the model are relatively higher which conclude that the model is well fitted for the system.

Comparisons of predicted models curve and the experimental curve are shown in Figures 7, 8, 9, and 10. Figures show that predicted Thomas and Yoon-Nelson curves are closer to experimental curves. Furthermore applying three models it is observed that $R^{2}$ values of Thomas and YoonNelson models are higher than the Adams-Bohart model. Hence Thomas and Yoon-Nelson models are found as the well fitted models for present lead adsorption system.

3.4. Error Function Analysis. Depending on $R^{2}$ value Thomas and Yoon-Nelson models were found as the well fitted models but for the findings of best fitted model error function analysis was used. Error function analysis is the most suitable optimization method to evaluate the best fitted model for the experimental data. Three error functions such as sum 
TABLE 5: Error function values of the models for lead adsorption by CRSD.

\begin{tabular}{lccccccccccccc}
\hline \multirow{2}{*}{$C_{0}(\mathrm{mg} / \mathrm{L})$} & $Q(\mathrm{~mL} / \mathrm{min})$ & $Z$ & \multicolumn{1}{c}{$(\mathrm{cm})$} & $\mathrm{pH}$ & \multicolumn{3}{c}{ Adams-Bohart } & \multicolumn{3}{c}{ Thomas } & \multicolumn{3}{c}{ Yoon-Nelson } \\
& & & & ERRSQ & HYBRID & MPSD & ERRSQ & HYBRID & MPSD & ERRSQ & HYBRID & MPSD \\
\hline 10 & 15 & 5 & 5.2 & 42.52 & 7.43 & 0.074 & 3.44 & 0.60 & 0.0060 & 5.22 & 0.91 & 0.0091 \\
20 & 15 & 5 & 5.2 & 222.77 & 17.81 & 0.178 & 5.74 & 0.45 & 0.0045 & 8.63 & 0.69 & 0.0069 \\
30 & 15 & 5 & 5.2 & 19.06 & 1.28 & 0.012 & 97.58 & 6.56 & 0.0656 & 90.93 & 6.11 & 0.061 \\
20 & 10 & 5 & 5.2 & 79.80 & 6.73 & 0.067 & 5.65 & 0.47 & 0.0047 & 7.32 & 0.6182 & 0.0061 \\
20 & 15 & 5 & 5.2 & 258.19 & 20.65 & 0.206 & 5.74 & 0.45 & 0.0045 & 8.63 & 0.6909 & 0.0069 \\
20 & 20 & 5 & 5.2 & 2267.94 & 337.83 & 3.378 & 0.123 & 0.018 & 0.00018 & 0.0006 & $9.18 E-05$ & $9.19 E-07$ \\
20 & 15 & 2 & 5.2 & 820.46 & 174.23 & 1.742 & $9.38 E-05$ & $1.99 E-05$ & $1.99 E-07$ & 42.52 & 9.0316 & 0.090 \\
20 & 15 & 5 & 5.2 & 222.77 & 17.81 & 0.178 & 5.74 & 0.45 & 0.0045 & 8.63 & 0.6909 & 0.0069 \\
20 & 15 & 7 & 5.2 & 15.09 & 1.10 & 0.011 & 2.83 & 0.20 & 0.0020 & 4.85 & 0.3539 & 0.0035 \\
20 & 15 & 5 & 3.1 & 506.39 & 301.96 & 3.019 & 0.095 & 0.056 & 0.00056 & 0.014 & 0.0085 & $8.56 E-05$ \\
20 & 15 & 5 & 5.2 & 222.77 & 17.81 & 0.178 & 5.74 & 0.45 & 0.0045 & 8.63 & 0.6909 & 0.0069 \\
20 & 15 & 5 & 6.4 & 212.01 & 22.01 & 0.220 & 7.97 & 0.82 & 0.0082 & 7.36 & 0.7643 & 0.0076 \\
\hline
\end{tabular}

of the squares of the errors (ERRSQ), hybrid fractional error function (HYBRID), and Marquardt's percent standard deviation (MPSD) were utilized for finding of the best fitted model. Square of the errors (ERRSQ) [21] is expressed as

$$
\text { ERRSQ }=\sum_{i=1}^{p}\left(q_{e}-q_{\text {Cal }}\right)^{2} .
$$

Hybrid fractional error function (HYBRID) [22] is expressed as

$$
\operatorname{HYBRID}=\frac{100}{p-n} \sum_{i=1}^{p}\left[\frac{\left(q_{e}-q_{\mathrm{cal}}\right)}{q_{e}}\right]^{2} .
$$

Marquardt's percent standard deviation (MPSD) [23] is obtained as

$$
\operatorname{MPSD}=\sum_{i=1}^{p}\left(\frac{\left(q_{e}-q_{\mathrm{cal}}\right)}{q_{e}}\right)^{2},
$$

where $q_{e}$ is the adsorption capacity found from the experiment $(\mathrm{mg} / \mathrm{g}), q_{\mathrm{cal}}$ is adsorption capacity calculated from models, $p$ is the number of parameters in the model, and $n$ is the number of data points. Lower value of ERRSQ, HYBRID, and MPSD and higher value of $R^{2}$ are the indication of best fitted model. Results of the error functions were illustrated in Table 5 from where it was suggested that Thomas model was the best fitted model for the present adsorption system.

3.5. Adsorption Mechanism. Efficiency of adsorption process is dependent on the surface of the adsorbent. From the results of adsorption process a theoretical/hypothetical structure was proposed which was shown in Figure 11. Due to chemical carbonization of rubber wood sawdust by sulphuric acid the double bond was generated in the rubber wood sawdust chain. Sulphuric acid was involved in dehydration process which generated the double bond. After dehydration process it was again oxidized by nitric acid and produces the lactone group. In this adsorption process the lead ions were attached to the carboxyl groups. So it can be concluded that the CRSD is worked as a cation exchange resin.
TABLE 6: Comparison of lead adsorption capacity of CRSD with other low-cost adsorbents.

\begin{tabular}{lcc}
\hline Low-cost adsorbent & $Q(\mathrm{mg} / \mathrm{g})$ & References \\
\hline Activated tea waste & 0.497 & {$[10]$} \\
Water hyacinth root & 10.94 & {$[11]$} \\
Granular activated carbon & 2.0132 & {$[12]$} \\
Manganese oxide coated zeolite & 0.363 & {$[13]$} \\
Treated granular activated carbon & 2.89 & {$[14]$} \\
Zeolite & 1.67 & {$[15]$} \\
Iron-coated zeolite & 2.28 & {$[15]$} \\
Ficus religiosa leaves & 16.42 & {$[16]$} \\
CRSD & 38.56 & Present study \\
\hline
\end{tabular}

3.6. Comparison with Other Adsorbents. The values of the lead adsorption capacities in column mode were compared in Table 6. Many researchers have examined efficiency of various low-cost adsorbents in column mode for the removal of lead ion. Comparisons of different adsorbents found in the literature were done on the basis of adsorption capacity. From the comparison CRSD can be considered as a valuable alternative for the removal of lead ion from aqueous solution.

3.7. Regeneration of the Adsorbent. Regeneration of adsorbent has an important significance in economical and environmental point of view. Reusability of the adsorbent was done by repeating the adsorption-desorption cycle for four times. For regeneration of carbonized sawdust the traditional methods like thermal activation, incineration, and land disposal were not used to restrict the environmental pollution. Regeneration was done by $0.2 \mathrm{M} \mathrm{HCl}$ solution and the experiment was repeated for four adsorption-desorption cycles. In first cycle $97.2 \%$ removal was achieved and in fourth cycle the removal efficiency of $88.1 \%$ was achieved (Figure 12). Removal efficiency decreases as cycle proceeds because the use of acid solution may destroy the binding sites of the CRSD or insufficient acid solution may allow the lead ion to remain in the binding sites. 


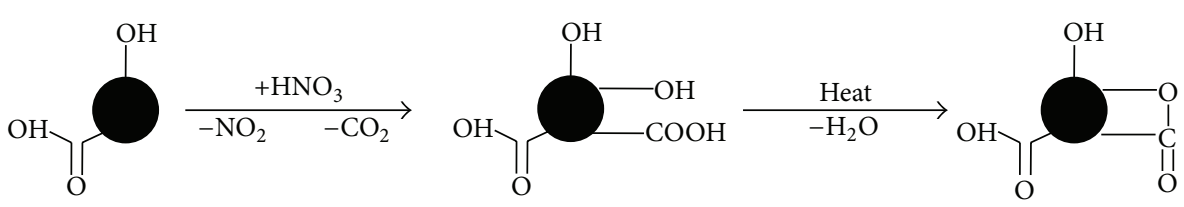

(a)

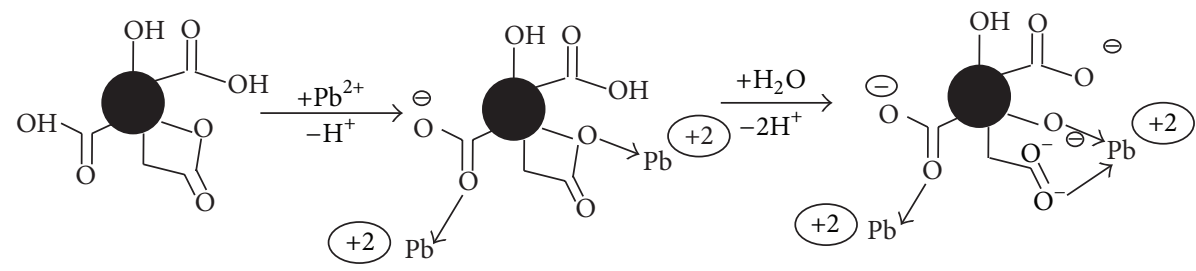

(b)

FIGURE 11: Proposed mechanism involved in the adsorption process: (a) oxidation by $\mathrm{HNO}_{3}$ and (b) binding mechanism of lead ion.

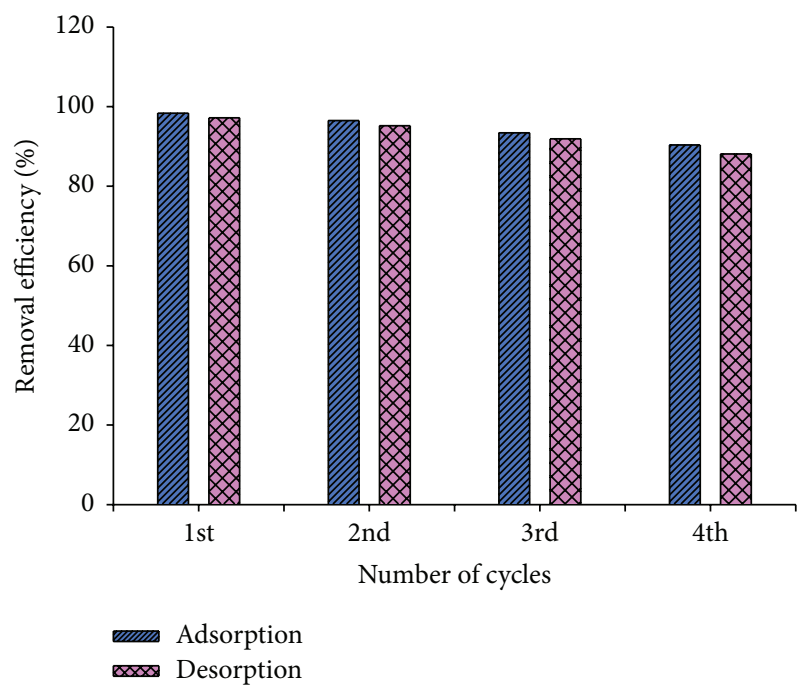

FIGURE 12: Adsorption/desorption efficiency of lead ion onto CRSD during different cycles (concentration $10 \mathrm{mg} / \mathrm{L}$, flow rate $15 \mathrm{~mL} / \mathrm{min}$, and bed depth $5 \mathrm{~cm}$ ).

\section{Conclusions}

The study concludes that removal of lead ion in a packed bed system using CRSD is an effective and feasible method. Behavior of breakthrough curve and the lead adsorption capacity is strongly influenced by flow rate, bed depth, influent concentration, and $\mathrm{pH}$. Breakthrough time increases with a higher bed depth, a lower flow rate, and a lower influent concentration. Adsorption capacities were high at the flow rate of $15 \mathrm{~mL} / \mathrm{min}$, bed depth of $7 \mathrm{~cm}$, influent concentration of $30 \mathrm{mg} / \mathrm{L}$, and $\mathrm{pH}$ of 5.2. This column adsorption process contributes a maximum adsorption capacity of $38.56 \mathrm{mg} / \mathrm{g}$. The prediction of breakthrough curves was obtained by using Adams-Bohart, Thomas, and Yoon-Nelson model. However the entire breakthrough curve was best predicted by Thomas model.

\section{Conflict of Interests}

The authors hereby declare no conflict of interests.

\section{Acknowledgment}

The authors are thankful to the Director of National Institute of Technology Agartala for providing necessary research facilities.

\section{References}

[1] M. R. Awual and M. M. Hasan, "A novel fine-tuning mesoporous adsorbent for simultaneous lead(II) detection and removal from wastewater," Sensors and Actuators, B: Chemical, vol. 202, pp. 395-403, 2014.

[2] A. P. Lim and A. Z. Aris, "Continuous fixed-bed column study and adsorption modeling: removal of cadmium (II) and lead (II) ions in aqueous solution by dead calcareous skeletons," Biochemical Engineering Journal, vol. 87, pp. 50-61, 2014.

[3] U. Guyo, J. Mhonyera, and M. Moyo, "Pb(II) adsorption from aqueous solutions by raw and treated biomass of maize stover-a comparative study," Process Safety and Environmental Protection, vol. 93, pp. 192-200, 2015.

[4] F. W. Sousa, A. G. Oliveira, J. P. Ribeiro, M. F. Rosa, D. Keukeleire, and R. F. Nascimento, "Green coconut shells applied as adsorbent for removal of toxic metal ions using fixed-bed column technology," Journal of Environmental Management, vol. 91, no. 8, pp. 1634-1640, 2010.

[5] A. Özer, "Removal of $\mathrm{Pb}$ (II) ions from aqueous solutions by sulphuric acid-treated wheat bran," Journal of Hazardous Materials, vol. 141, no. 3, pp. 753-761, 2007.

[6] K. Kelly-Vargas, M. Cerro-Lopez, S. Reyna-Tellez, E. R. Bandala, and J. L. Sanchez-Salas, "Biosorption of heavy metals in polluted water, using different waste fruit cortex," Physics and Chemistry of the Earth, Parts A/B/C, vol. 37-39, pp. 26-29, 2012.

[7] L. H. Velazquez-Jimenez, A. Pavlick, and J. R. Rangel-Mendez, "Chemical characterization of raw and treated agave bagasse and its potential as adsorbent of metal cations from water," Industrial Crops and Products, vol. 43, no. 1, pp. 200-206, 2013.

[8] Y. Long, D. Lei, J. Ni, Z. Ren, C. Chen, and H. Xu, "Packed bed column studies on lead(II) removal from industrial wastewater 
by modified Agaricus bisporus," Bioresource Technology, vol. 152, pp. 457-463, 2014.

[9] G. Tchobanologus, F. L. Burton, and H. D. Stensel, Eds., Wastewater Engineering: Treatment and Reuse, Tata McGrawHill, New Delhi, India, 2003.

[10] M. K. Mondal, "Removal of $\mathrm{Pb}$ (II) ions from aqueous solution using activated tea waste: adsorption on a fixed-bed column," Journal of Environmental Management, vol. 90, no. 11, pp. 32663271, 2009.

[11] T. Mitra, B. Singha, N. Bar, and S. K. Das, "Removal of Pb (II) ions from aqueous solution using water hyacinth root by fixed-bed column and ANN modeling," Journal of Hazardous Materials, vol. 273, pp. 94-103, 2014.

[12] C. P. Dwivedi, J. N. Sahu, C. R. Mohanty, B. R. Mohan, and B. C. Meikap, "Column performance of granular activated carbon packed bed for $\mathrm{Pb}$ (II) removal," Journal of Hazardous Materials, vol. 156, no. 1-3, pp. 596-603, 2008.

[13] R. Han, W. Zou, H. Li, Y. Li, and J. Shi, "Copper(II) and lead(II) removal from aqueous solution in fixed-bed columns by manganese oxide coated zeolite," Journal of Hazardous Materials B, vol. 137, no. 2, pp. 934-942, 2006.

[14] J. Goel, K. Kadirvelu, C. Rajagopal, and V. K. Garg, "Removal of lead(II) by adsorption using treated granular activated carbon: batch and column studies," Journal of Hazardous Materials B, vol. 125, no. 1-3, pp. 211-220, 2005.

[15] T. C. Nguyen, P. Loganathan, T. V. Nguyen, S. Vigneswaran, J. Kandasamy, and R. Naidu, "Simultaneous adsorption of Cd, Cr, $\mathrm{Cu}, \mathrm{Pb}$, and $\mathrm{Zn}$ by an iron-coated Australian zeolite in batch and fixed-bed column studies," Chemical Engineering Journal, vol. 270, pp. 393-404, 2015.

[16] S. Qaiser, A. R. Saleemi, and M. Umar, "Biosorption of lead from aqueous solution by Ficus religiosa leaves: batch and column study," Journal of Hazardous Materials, vol. 166, no. 2-3, pp. 9981005, 2009.

[17] J. Cruz-Olivares, C. Pérez-Alonso, C. Barrera-Díaz, F. UreñaNuñez, M. C. Chaparro-Mercado, and B. Bilyeu, "Modeling of lead (II) biosorption by residue of allspice in a fixed-bed column," Chemical Engineering Journal, vol. 228, pp. 21-27, 2013.

[18] W. Song, X. Xu, X. Tan et al., "Column adsorption of perchlorate by amine-crosslinked biopolymer based resin and its biological, chemical regeneration properties," Carbohydrate Polymers, vol. 115, pp. 432-438, 2015.

[19] S. Chen, Q. Yue, B. Gao, Q. Li, X. Xu, and K. Fu, "Adsorption of hexavalent chromium from aqueous solution by modified corn stalk: a fixed-bed column study," Bioresource Technology, vol. 113, pp. 114-120, 2012.

[20] D. Bulgariu and L. Bulgariu, "Sorption of $\mathrm{Pb}$ (II) onto a mixture of algae waste biomass and anion exchanger resin in a packedbed column," Bioresource Technology, vol. 129, pp. 374-380, 2013.

[21] A. Günay, E. Arslankaya, and I. Tosun, "Lead removal from aqueous solution by natural and pretreated clinoptilolite: adsorption equilibrium and kinetics," Journal of Hazardous Materials, vol. 146, no. 1-2, pp. 362-371, 2007.

[22] S. Pal, D. Mal, and R. P. Singh, "Cationic starch: an effective flocculating agent," Carbohydrate Polymers, vol. 59, no. 4, pp. 417-423, 2005.

[23] A. C. A. de Lima, R. F. Nascimento, F. F. de Sousa, J. M. Filho, and A. C. Oliveira, "Modified coconut shell fibers: a green and economical sorbent for the removal of anions from aqueous solutions," Chemical Engineering Journal, vol. 185-186, pp. 274284, 2012. 

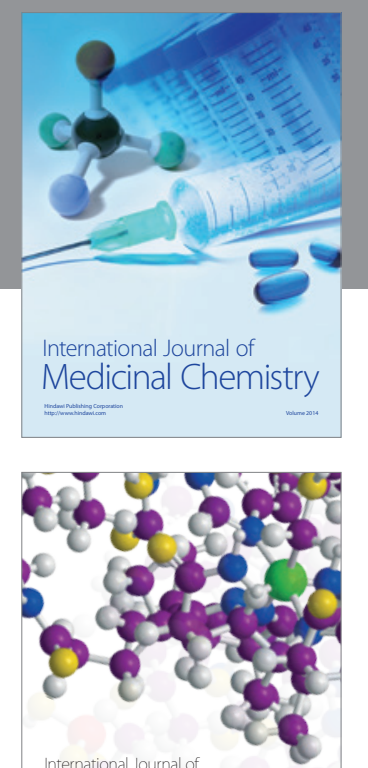

\section{Carbohydrate} Chemistry

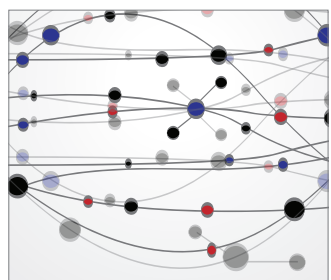

The Scientific World Journal
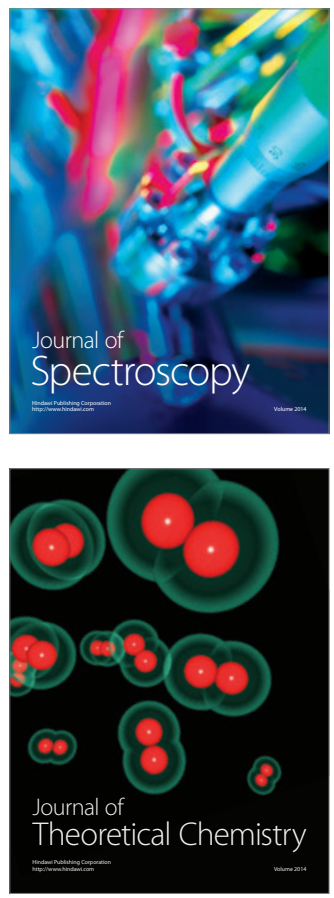
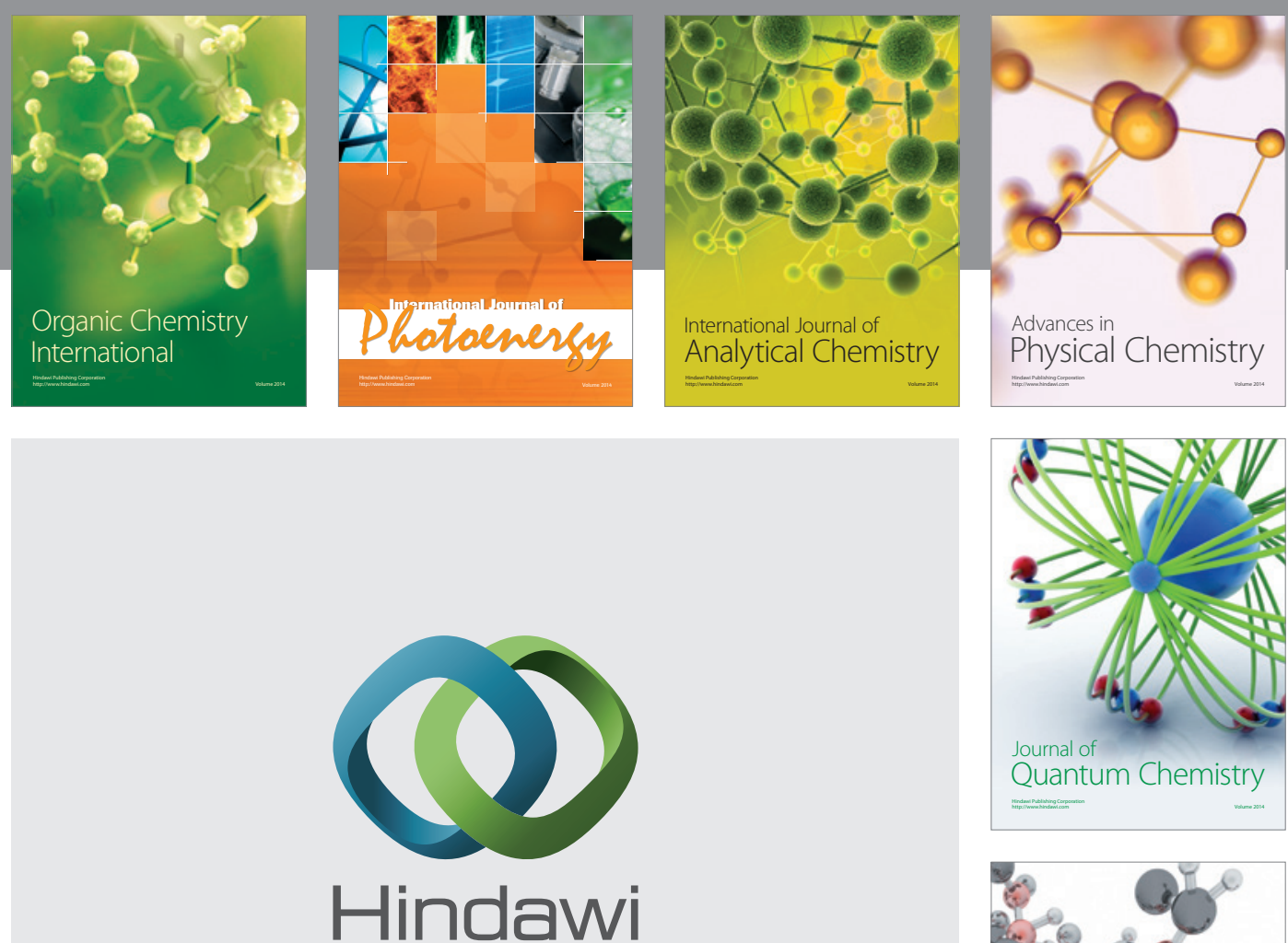

Submit your manuscripts at

http://www.hindawi.com

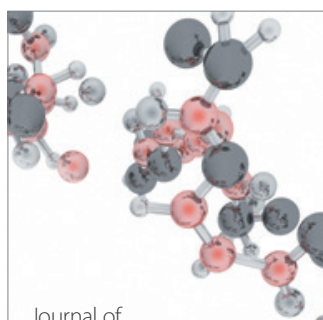

Analytical Methods

in Chemistry

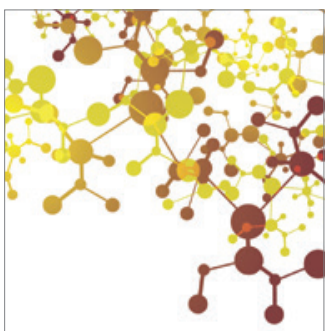

Journal of

Applied Chemistry

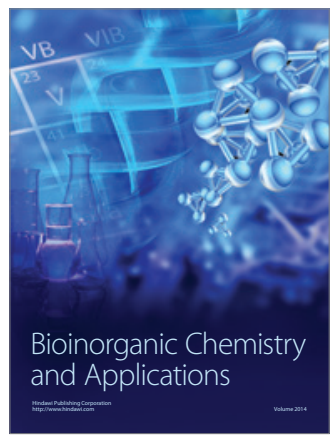

Inorganic Chemistry
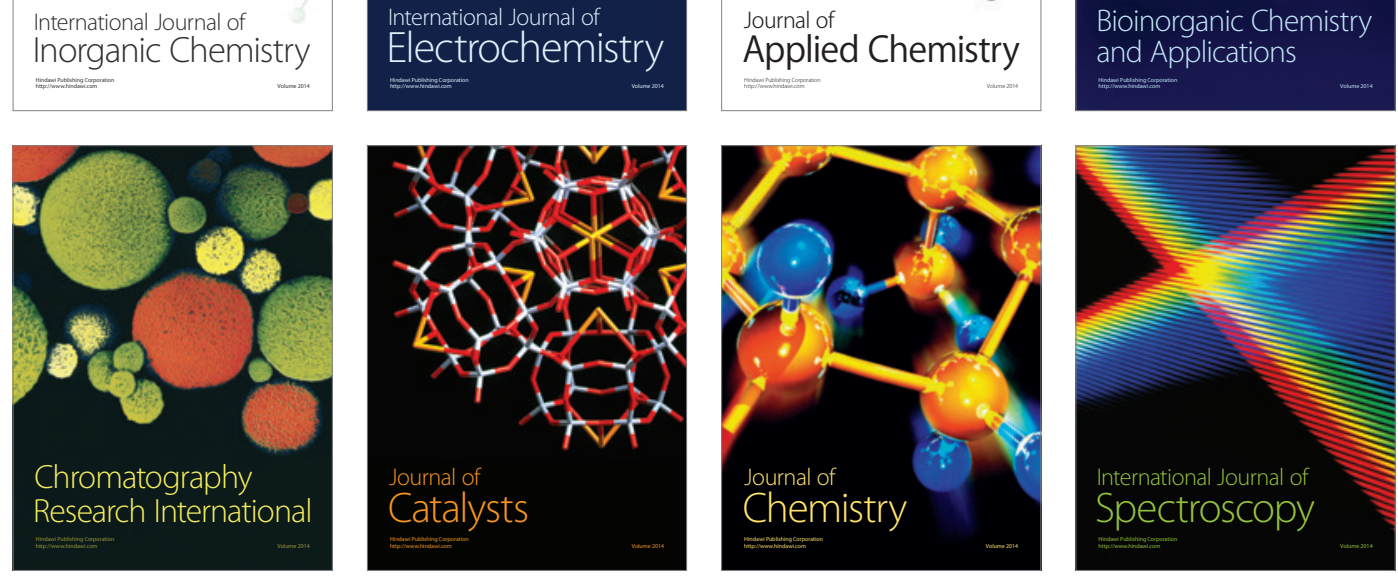